\title{
A policy framework for sustainability in developing countries: applying value chain theory to a society's hierarchy of needs
}

\author{
P. R. Walsh \\ Ted Rogers School of Management, Ryerson University, Canada
}

\begin{abstract}
This paper serves to refine a framework for prioritizing policy related to sustainable development that combines elements of A.H. Maslow's hierarchy of needs theory with M.E. Porter's value chain theory. The research community has provided a variety of methodologies related to the determination of measurement indicators associated with sustainable development. The use of aggregate indices as indicators of sustainable development has been supported by researchers in the latest literature on sustainable development. Indices-based research however appears to have had little influence on policy development because sustainability indicators in themselves provide no direction for how the information can be used to become more sustainable. Using recent index measures, an appropriate balance of social, economic and environmental sustainability is examined so that policy makers may be provided some direction in regards to appropriate and socially-just resource priorities. The model that forms the basis for this framework is tested through hierarchal regression analysis using data from 45 developing countries and compared to previous testing using earlier data. These latest results confirm the values chain framework whereby the satisfaction of society's physiological needs through the prioritization of policies related to social and environmental sustainability is the principle motivator for moving on to the attainment of higher order needs such as increased levels of sustainable development.

Keywords: sustainable development, developing countries, hierarchy of needs, value chain, sustainability indicators.
\end{abstract}




\section{Introduction}

Maslow [1], in his formulation of a positive theory of motivation, suggested that there was a "hierarchy of needs" within individuals that were basic to their existence and therefore represented "goals" to be achieved. He argued that each of these goals is related to one another and that a hierarchy of need exists given the conditions faced by the individual and that certain needs would be satisfied first. Once that goal was satisfied, then an individual would seek to satisfy the next goal in their hierarchy of needs. He characterized these basic needs in order of prepotency as; physiological, safety, love, esteem and self-actualization. These terms have been represented in the literature as a "pyramid" model as shown in Figure 1.

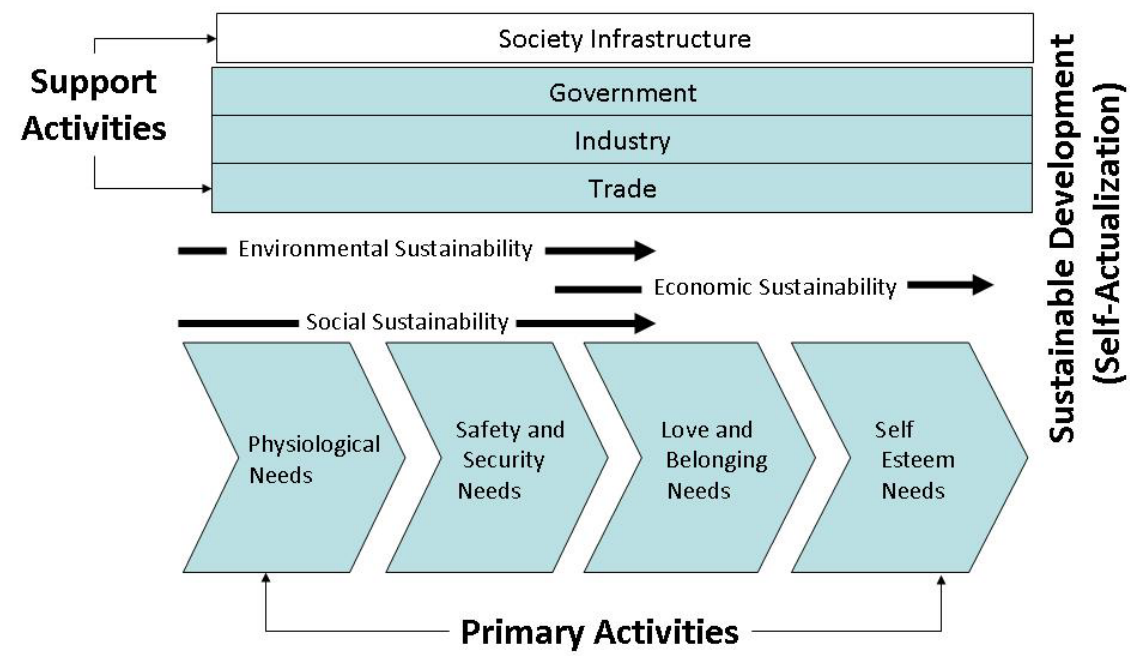

Figure 1: $\quad$ Value chains framework [5].

Some researchers have recently used Maslow's hierarchy of needs theory in their creation of models that specifically address global sustainable development. Melloul and Collin [2] employed the pyramid model of Maslow's theory to the case of groundwater management in Israel by relating the hierarchy of societal needs to a hierarchy of groundwater management needs where physiological, safety, love, esteem and fulfillment needs equated to physical ground water quantity, water quality, education (awareness) and water resource sustainability respectively. As part of a quantitative analysis of global sustainable development Udo and Jansson [3] found that by measuring sustainable development in terms of a combination of measures related to social, technological and environmental sustainability they were able to group nations into five categories consistent with Maslow's hierarchy of needs. They found that nations could be characterized as self-actualized when exhibiting high social and high technological sustainability 
measures that enabled them to contribute more effort in terms of environmental sustainability. In contrast, those nations with low social and low technological sustainability measures were characteristically deficient in the practice of satisfying their own basic needs, let alone environmental sustainability practices.

Porter [4] presented the value chain analysis as a model for the identification and measurement of those activities comprising a firm's value chain (Figure 2). A "value chain" is a series of activities within the firm related to the provision of a product or service that provides value to the firm's customers. This resultant value leads to positive financial outcomes for the firm when customers are willing to pay an amount in excess of the costs associated with creating that value.

There are two distinct sets of activities, primary and secondary, that a firm undertakes within the value chain. Primary activities are directly related to the provision of products or services sold to a customer. Support activities relate to those functions contained within a firm's infrastructure that assist with the undertaking of the firm's primary activities. These distinct sets of activities are inter-dependent and how one activity is conducted impacts on other activities within the value chain of the firm. An example of this interdependence can be found in technology development activities where research and development can influence the design of a product or service and that design will have some impact on the outbound logistics or distribution activity if the design involves significant changes to packaging or shipment size.

\section{Applying value chain theory to a society's hierarchy of needs}

A framework for applying Porter's Value Chain to a society's hierarchy of needs as developed by Walsh [5] is shown in Figure 1. The three principal elements of sustainable development; social, economic and environmental sustainability can be represented by one or more of the primary activities. Udo and Jansson [3] characterized advanced environmental sustainability as a state of "selfactualization". Social sustainability has been described by Goodland [6] (p.2) as a "Cohesion of community for mutual benefit, connectedness between groups of people, reciprocity, tolerance, compassion, patience, forbearance, fellowship, love, commonly accepted standards of honesty, discipline and ethics", similar to Maslow's descriptions of the love/belonging and safety/security needs. Economic sustainability has been defined as the achievement and maintenance of capital which has its parallel with personal achievement and stability that Maslow associated with the esteem need.

The supporting activities within the values chain are related to the infrastructure within society itself. Much like the infrastructure of the firm, society infrastructures contain, albeit in different forms, support systems such as government (human resource management), industry (technology and development) and trade organizations (procurement). It is the supporting activities of the society infrastructure that contributes to the ability of society to 
achieve and uphold societal values that satisfy the physiological, safety, love and self-esteem needs required to achieve sustainable development. Like Porter's value chain, all activities within the values chain are inter-dependent and must be managed together in order to succeed. To illustrate this interdependence, government policies can influence the allocation of resources so that adequate supplies of food and water supply exist to meet the physiological needs of their society but the availability of those resources may have resulted from taxation of employment income (self-worth and esteem needs) created by trade mechanisms. This framework serves to provide policy developers with a model for identifying which needs are deficient and then determining the interrelationship of activities required to satisfy those deficiencies.

\section{Sustainable development and sustainability indicators}

There are generally two types of sustainable development measures that are utilized in the literature. The first type is comprised of either shortened sets of so-called "headline indicators" (e.g. GDP or per capita income) centered on themes (e.g. water quality), jurisdictions (e.g. specific regions) or sectors (e.g. energy production). The second type is an aggregate of indices derived from variable measures related to economic, social and environmental sustainability $[7,8]$.

Combining social, economic and environmental indices as indicators of sustainable development has been supported by researchers in the latest literature on sustainable development [9-14]. Two of the more popular indices include the Human Development Index (HDI) which aggregates income (gross domestic product per capita), education (adult literacy rate) and health (life expectancy at birth) and the Environmental Sustainability Index (ESI) - now modified to be the Environmental Performance Index- an aggregation of indicators related to environmental health impacts on humans (disease, water pollution, air pollution) and ecosystem vitality (air/water pollution effects, biodiversity and habitat, productive natural resources-forestry, fisheries and agriculture, and climate change). In addition to these sustainability measures, other indices include the International Food Policy Research Institute's (IFPRI) Global Hunger Index that measures malnourishment in adults and children as well as infant mortality rates and the Global Peace Index (GPI) that provides a measure of the existence or absence of societal safety and security. This latter index is published by the Institute for Economics and Peace.

Furthermore, the World Economic Forum (WEF) publishes two indices related to societal and economic sustainability. The first, the Global Gender Gap Index (GGI), is a report that identifies the magnitude of the gap existing between men and women in four important areas: economic participation and opportunity, political empowerment, educational attainment and, health and survival. The second, the Global Competitiveness Index

(GCI) measures what is termed "The 12 pillars of competitiveness" such as the institutional environment, extensive and efficient infrastructure, 
macroeconomic stability, a healthy and educated workforce (at a primary level), quality higher education and training (secondary and tertiary level), healthy market competition, labour market efficiency, financial market sophistication, technology readiness, market size, business sophistication and innovation.

Various researchers have created their own indices including Ronchi et al's [8] sustainable development index of a limited set of headline indicators related to socio-economic development, environmental quality and resource and Distaso's [15] index that extends elements of the HDI to include specific environmental indicators such as emission rates and percentages of environmentally protected areas. One other recent index that combines data from the 2004-2005 Global Competitiveness Index and the 2005 ESI to determine the linkage of national supply chains to sustainable development was developed by Vachon and Mao [16].

A criticism of the indices-based approach to measuring sustainable development is that it seems to have had little influence on policy development [13]. The reason for this lack of influence is that these measures provide no direction for how the information can be used to become more sustainable [17]. A needs approach [18] that focuses less on societal rights when determining sustainable development policies and more on the needs of society could assist policy makers in terms of providing direction from the results of the data measured. A needs approach would also be more consistent with the Brundtland Report's definition of "sustainable development" as the "development that meets the needs of the present without compromising the ability of future generations to meet their own needs". [19]

\section{Data and methods}

Following on the work of Walsh [5] that relied on 2009 data, more recent data (2010) was gathered for the different sustainability indices used in the framework (See Table 1). Standardized scores from 45 developing nations (See Table 2) were compiled for each of the indices and the sum total of these social, economic and environmental sustainability measures represent the sustainable development score for that country (SD).

A hierarchal forward method of multiple regression analyzed the predictor variables (Index scores for the EPI, GHI, GPI, GGI and GCI) from the model one at a time in an order determined by their relative correlative strength with the criterion variable, SD. The impact of adding each predictor variable was assessed and any variable that did not significantly add to the success of the model was excluded. Collinearity diagnostics were applied in order to test for any predictive variables that may have been highly correlated and which may limit the ability to infer the relative contribution of each predictor variable. In such circumstances, these predictive variables would be removed. 
Table 1: $\quad$ Values chain and chosen indices.

\begin{tabular}{|c|c|}
\hline Component of the Values Chain & Related Sustainability Indicator \\
\hline Physiological Needs & $\begin{array}{l}\text { Global Hunger Index }(\mathrm{GHI})^{1} \\
\text { Environmental Performance Index } \\
\begin{array}{ll}(\mathrm{EPI})^{2} & \\
* & \text { Environmental health } \\
\text { impacts on humans } \\
* & \text { Ecosystem Vitality }\end{array}\end{array}$ \\
\hline Safety and Security Needs & $\begin{array}{ll}\text { Global Peace Index }(\mathrm{GPI})^{3} \\
* & \begin{array}{l}\text { Measures of societal safety } \\
\text { and security }\end{array}\end{array}$ \\
\hline Love and Belonging Needs & $\begin{aligned} \text { Gender } & \text { Gap Index }(\mathrm{GGI})^{4} \\
* & \text { Economic Participation and } \\
& \text { Opportunity } \\
* & \text { Educational Attainment } \\
* & \text { Political Empowerment } \\
* & \text { Health and Survival }\end{aligned}$ \\
\hline Self-Esteem Needs & $\begin{array}{cl}\text { Global Competitiveness Index }(\mathrm{GCI})^{5} \\
\quad \text { Basic Requirements } \\
+ & \text { Efficiency Enhancers } \\
* & \text { Innovation and } \\
& \text { Sophistication Factors }\end{array}$ \\
\hline Self-Actualization Needs & Sustainable Development (SD) \\
\hline
\end{tabular}

${ }^{1}$ International Food Policy Research Institute (IFPRI) 2010

${ }^{2}$ Yale Center for Environmental Law and Policy, CIESIN Columbia University, WEF and JRCEC (2010)

${ }^{3}$ Institute for Economics and Peace 2010

${ }^{4}$ World Economic Forum (WEF) 2010

${ }^{5}$ World Economic Forum (WEF) 2009-2010 


\begin{tabular}{|c|c|}
\hline Ө & 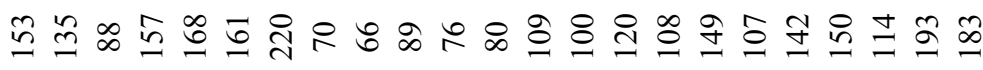 \\
\hline ְ. & 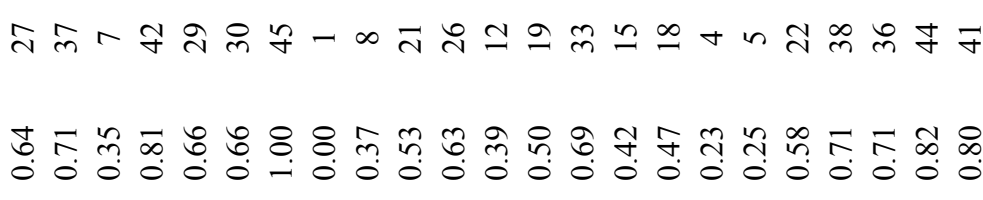 \\
\hline ত্ত & 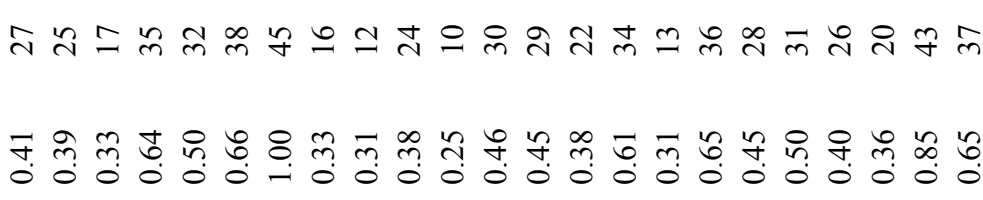 \\
\hline 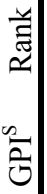 & 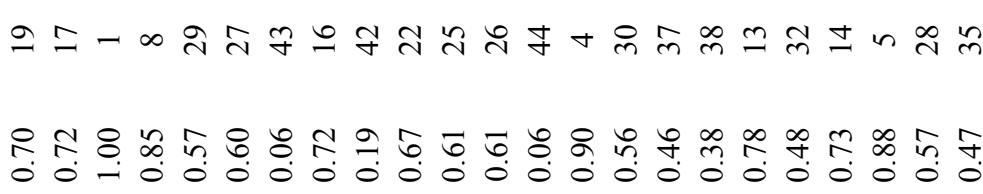 \\
\hline$\stackrel{\sim}{\Xi}$ & 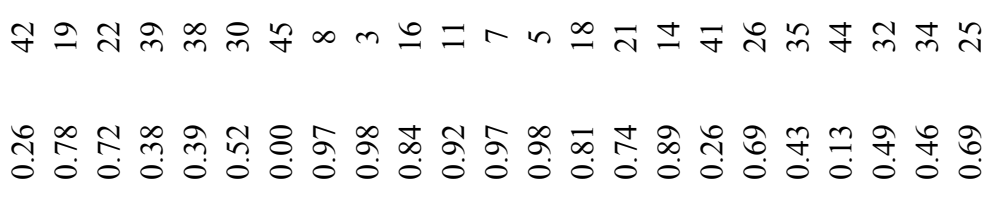 \\
\hline 足 & 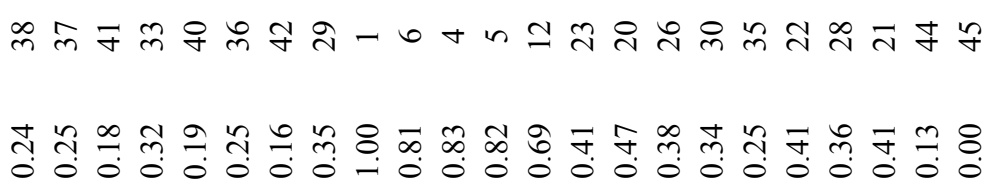 \\
\hline 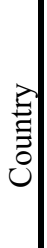 & 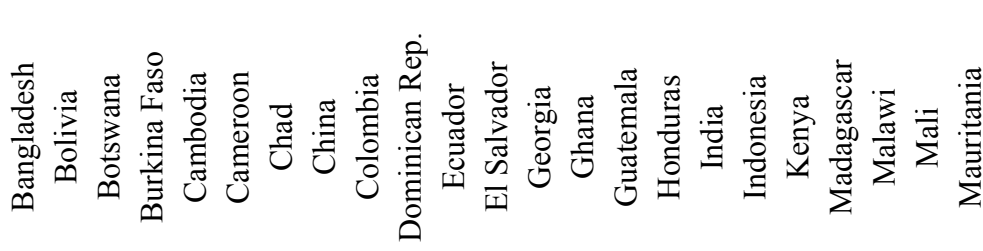 \\
\hline
\end{tabular}




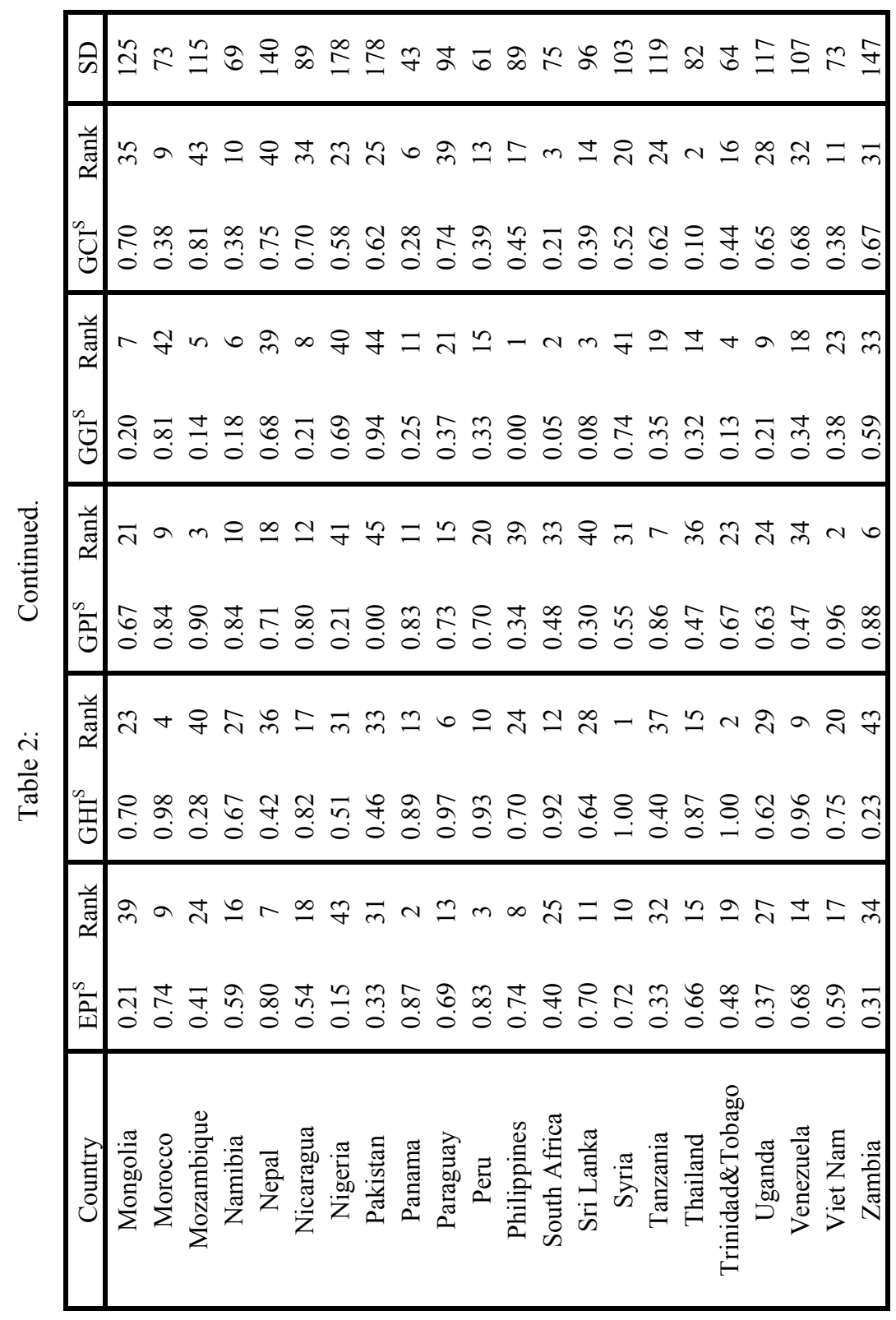




\section{Results}

The results of the regression are shown in Table 3. Consistent with the results of the earlier work of Walsh (2011), the greatest contribution to higher levels of sustainable development in developing nations is made by attending to the physiological (GHI $\Delta \mathrm{R} 2=.584$, EPI $\Delta \mathrm{R} 2=.182)$, love and belonging (GGI $\Delta \mathrm{R} 2=.083)$ and, safety and security needs of society (GPI $\Delta \mathrm{R} 2=.060)$. As with the previous work, the self-actualization needs as measured by the GCI $(\Delta \mathrm{R} 2=.058)$ contributed least to the level of sustainable development.

Table 3: Results of multiple regression analysis - hierarchal forward method.

\begin{tabular}{|c|c|c|c|c|c|c|}
\hline Model & $\mathrm{R}$ & $\mathrm{R}^{2}$ & Adj. $R^{2}$ & Std. Error & $\Delta \mathrm{R}^{2}$ & $\Delta \mathrm{F}$ \\
\hline 1 & .764 & .584 & .574 & 26.65900 & .584 & 60.357 \\
\hline 2 & .875 & .766 & .754 & 20.24779 & .182 & 32.542 \\
\hline 3 & .921 & .849 & .838 & 16.46907 & .083 & 22.484 \\
\hline 4 & .953 & .908 & .899 & 12.97353 & .060 & 26.070 \\
\hline 5 & .983 & .966 & .962 & 7.97365 & .058 & 66.892 \\
\hline
\end{tabular}

The diagnostic test for collinearity (Table 4) among the needs variables resulted in reasonable tolerances $(>.10)$ and VIF's $(<10)$ that limit concerns about multi-collinearity effects on the results.

Table 4: $\quad$ Exclusion of variables analysis.

\begin{tabular}{|c|c|c|c|}
\hline \multicolumn{2}{|c|}{ Model $^{\mathrm{a}}$} & Tolerance & VIF \\
\hline \multirow{4}{*}{1} & EPI & .670 & 1.492 \\
\cline { 2 - 4 } & GPI & .999 & 1.001 \\
\cline { 2 - 4 } & GGI & .852 & 1.174 \\
\cline { 2 - 4 } & GCI & .736 & 1.358 \\
\hline \multirow{4}{*}{2} & EPI & .659 & 1.518 \\
\cline { 2 - 4 } & GPI & .914 & 1.094 \\
\cline { 2 - 4 } & GCI & .712 & 1.405 \\
\hline \multirow{3}{*}{3} & GPI & .905 & 1.105 \\
\cline { 2 - 4 } & GCI & .710 & 1.409 \\
\hline \multirow{2}{*}{4} & GCI & .707 & 1.415 \\
\hline
\end{tabular}

${ }^{a}$ All model predictors significant to .001 


\section{Discussion}

The application of the results of the analysis of 2010 data supports previous work that suggested less- developed nations must address the physiological needs of society (as put forward by Maslow) by implementing environmental sustainability policies in tandem with social sustainability policies so that resource allocation priorities are balanced between the two.

Policy makers in developing nations should focus on initiatives that balance available resources between social and environmental sustainability needs. For example, in the African nations of Chad and the Republic of Mali the levels of sustainable development are the lowest amongst developing nations. The framework would indicate that policies which stimulate improvements in the social and environmental welfare of those countries would have a greater impact on sustainable development and encourage the pursuit of sustainable economic growth.

Some countries may rank highly on most of the sustainability indicators but still fall behind on certain measures, such as in the case of Thailand where the GPI score is comparatively lower than other scores. For the Thai government, policies and resource allocation that can improve the safety and security needs of its society would enhance its status as a leader in sustainable development among developing countries. The value needs framework has implications for regional policy development. In Central America, Panama ranks at the top in the region for meeting the physiological needs and the self-esteem needs of its society but it ranks lower in the region on the safety need. Policy makers in Panama might consider allocating more resources to addressing those social sustainability measures related to a safer society in order to improve its overall level of sustainable development. Guatemala ranks last in the region in sustainable development due to its lower EPI and GHI scores (physiological needs) and it's low GGI score (belonging needs). According to the values chain model, policy makers in Guatemala should focus resources on environmental and social sustainability measures firstly and then once they have improved their ability to meet their physiological needs they can begin considering gender equity policies. As discussed later in the limitations section, caution must be exercised in relying completely on these results and other country-specific factors may need to be considered.

\section{$7 \quad$ Limitations and future research}

The sample used $(n=45)$ was limited by the availability of data for the sustainability measures that make up the values chain framework and therefore the extent to which one can generalize the relative strengths of the indices used on the level of sustainable development is limited to that sample. The sample could be expanded to include other developing countries as well as developed nations in order to allow for greater insight into the influence of the satisfaction of needs on the level of sustainable development. As most developed countries have presumably satisfied their primary needs, it is not unreasonable to expect 
that the satisfaction of higher-order needs has a greater influence on the level of sustainable development. Furthermore, there are a number of combinations of measurable components of sustainability that might be more appropriate in providing policy direction when applied to this framework.

\section{References}

[1] Maslow, A.H., A theory of human motivation. Psychological Review, 50, 370-396, 1943.

[2] Matania, E., Yaniv, I., Resource priority, fairness, and equality-efficiency compromises. Social Justice Research, 20(4), 497-510, 2007.

[3] Melloul, A.J., Collin, M.L., Prioritization of sustainable groundwater management needs: The case of Israel's stressed coastal aquifer. Environment, Development and Sustainability, 4(4), 347-360, 2002.

[4] Udo, V.E., Jansson, P.M., Bridging the gaps for global sustainable development: A quantitative analysis. Journal of Environmental Management, 90(12), 3700-3707, 2009.

[5] Porter, M.E., Changing patterns of international competition. California Management Review, 28(2), 9-40, 1986.

[6] Walsh, P., Creating a "Values" Chain for Sustainable Development in Developing Nations: Where Maslow meets Porter. Environment Development and Sustainability (Forthcoming), 2011.

[7] Goodland, R., Sustainability: Human, Social, Economic and Environmental, Encyclopedia of Global Environmental Change. John Wiley \& Sons: London, 2002.

[8] Ronchi, E., Federico, A., Musmeci, F., A system oriented integrated indicator for sustainable development in Italy. Ecological Indicators, 2(1/2), 193-210, 2002.

[9] Mayer, A.L., Thurston, H.W., Pawlowski, C.W., The multidisciplinary influence of common sustainability indices. Frontiers in Ecology and the Environment, 2(8), 419-426, 2004.

[10] Chen, Y., Su, X., Hipel, K.W., Index aggregation approach to comparing the performance of emerging and developed countries. Socio-Economic Planning Sciences, 43(1), 25-39, 2009.

[11] Moffat, I., A preliminary analysis of composite indicators of sustainable development. International Journal of Sustainable Development and World Ecology, 15(2), 81-87, 2008.

[12] Moran, D.D., Wackernagel, M., Kitzes, J.A., Goldfinger, S.H., Boutaud, A., Measuring sustainable development - Nation by nation. Ecological Economics, 64(2), 470-474, 2008.

[13] Morse, S., Greening the United Nations' Human Development Index. Sustainable Development, 11(4), 183-198, 2003.

[14] Neumayer, E., The human development index and sustainability - a constructive proposal. Ecological Economics, 39(1), 101-114, 2001. 
674 Sustainable Development and Planning V

[15] Webersik, C., Wilson, C., Achieving environmental sustainability and growth in Africa: the role of science, technology and innovation, Journal of Sustainable Development, 17(6), 400-413, 2009.

[16] Distaso, A., Well-being and/or quality of life in EU countries through a multidimensional index of sustainability. Ecological Economics, 64(1), 163- 180, 2007.

[17] Vachon, S., Mao, Z., Linking supply chain strength to sustainable development: a country-level analysis. Journal of Cleaner Production, 16(15), 1552-1560, 2008.

[18] Murray, A., Ray, I., Nelson, K.L., An innovative sustainability assessment for urban wastewater infrastructure and its application in Chengdu, China. Journal of Environmental Management, 90(11), 3553-3560, 2009.

[19] Redclift, M., Sustainable development (1987-2005): An oxymoron comes of age. Sustainable Development, 13(4), 212-227, 2005.

[20] Cabezas, H., Pawlowski, C.W., Mayer, A.L., Hoagland, N.T., Sustainable systems theory: ecological and other aspects. Journal of Cleaner Production, 13(5), 455-467, 2005. 